\title{
Vectors and vector-borne diseases in Qatar: current status, key challenges and future prospects
}

\author{
F. Schaffner ${ }^{1 * "}$, D. Bansal ${ }^{2 \#}$, K. Mardini ${ }^{3}$, S.A. Al-Marri ${ }^{2}$, M.H.J. Al-Thani ${ }^{2}$, H. Al-Romaihi ${ }^{2}$, A.A. Sultan ${ }^{4}$, M. Al-Hajri ${ }^{2}$ \\ and E.A.B.A. Farag ${ }^{2 *}$ \\ ${ }^{1}$ Francis Schaffner Consultancy, Lörracherstrasse 50, 4125 Riehen, Switzerland; ${ }^{2}$ Ministry of Public Health, P.O. Box \\ 42, Doha, Qatar; ${ }^{3}$ Friends of the Environment Center, P.O. Box 1175, Doha, Qatar; ${ }^{4}$ Department of Microbiology and \\ Immunology, Weill Cornell Medicine, Cornell University, P.O. Box 24144, Doha, Qatar; fschaffner.consult@gmail.com; \\ eabdfarag@moph.gov.qa; "these authors contributed equally to this work.
}

Received: 2 July 2020 / Accepted: 5 February 2021

(C) 2021 F. Schaffner et al.

\section{RESEARCH ARTICLE}

\begin{abstract}
Vector-borne diseases (VBDs) have re-emerged worldwide due to urbanisation, increase in travel and climate change, becoming a major and serious threat to global public health. In Qatar, the concern has recently risen because of the attribution of the soccer 2022 FIFA World Cup Qatar ${ }^{\mathrm{rm}}$, which necessitates fulfilling requirements in terms of prevention and preparedness for disease transmission, including VBDs. This review presents a general overview about current status of vectors and VBDs in Qatar and addresses key challenges and future prospects of control programmes and strategies. It is based on a vector control situation analysis and needs assessment performed during an expert mission in Qatar, November 2017, organised by the WHO Eastern Mediterranean Regional Office and achieved in collaboration with the Ministry of Public Health of Qatar and other local stakeholders. The situation of vectors and VBDs of public health importance in Qatar was analysed based on a systematic literature review by December 31, 2019. The literature reveals that no locally transmitted VBD cases have been recorded in Qatar, but cases were recorded among expatriate workers and travellers who returned from an endemic country. However, data on VBD cases remain scarce except for malaria. The presence of native arthropod vectors is underrecorded to date. A compilation of literature data revealed reports of 30 vector species, including 20 mosquitoes, 2 fleas, 1 louse, 1 fly, and 6 ticks. Overall, Qatar benefits currently from a good surveillance of some VBDs (malaria) and has some capacities in vector control, but no national plan exists, and vector surveillance is in its infancy. In Qatar, clear needs exist in capacity in epidemiology and vector entomology, as well as on the organisational level, and a number of measures are suggested to mitigate and improve VBD risk assessment and management. There is an urgent need to define sustainable solutions for VBD control, management and prevention, and a number of recommendations are suggested.
\end{abstract}

Keywords: vector-borne diseases, mosquitoes, ticks, sand flies, flies, lice, Qatar

\section{Introduction}

In recent years, the importance of vector-borne diseases (VBDs) has increased at global and regional levels (Valenzuela and Aksoy, 2018). Many of these vectors are bloodsucking arthropods that include in particular mosquitoes, sand flies, and ticks. Human population growth, intensive human and wildlife movement, urbanisation and environmental change including climate change have a significant impact on pathogen transmission (Weaver, 2013). While there is a known increase of incidence of some VBDs such as dengue in the Eastern Mediterranean region (Humphrey et al., 2016), little information is available for the State of Qatar. However in Qatar, structural changes exist 
that appear to be risk factors to facilitate VBD local upsurge and pathogen transmission. First, a rapid increase of Qatari population in general is observed due to the arrival of a high number of migrants (mainly from India, Nepal and Sudan) that represent more than $75 \%$ of the population $(\times 3.8$ over 15 years $)^{1}$. There is also a considerable influx of tourists ( $\times 7.5$ over 14 years). ${ }^{1}$ Mobility of human populations is (Eder et al., 2018) and migrants and tourists originating from VBD endemic countries may possibly introduce pathogens into Qatar. Second, there is a high proportion and increase of urban population (more than $99 \% ; \times 4.7$ over 15 years). ${ }^{1}$ The urban context has demonstrated to increase the chances of VBD transmission, in particular for those amplified by humans (rather than other non-human hosts) (Eder et al., 2018). Finally, Qatar faces a booming of freight air transport $(\times 24.6$ over 14 years $)$ as well as a huge increase of port traffic ( $+29 \%$ over 14 years) and globally of merchandise import $(\times 10.6$ over 14 years $) .{ }^{1}$ Here the associated risk is the increase of introduction of vectors, pathogen-infected or not (Tatem et al., 2006).

In VBD non-endemic countries like the State of Qatar, the first step in prevention and control of vector-borne pathogen transmission requires the identification of potential vectors and of the human and animal populations at-risk. Adequate risk assessment, early detection, prevention and control of endemic and emerging VBDs demand approaches other than or in addition to those developed for non-VBDs (Braks et al., 2011). Initial assessment of VBD risk can be estimated from the current presence or absence of the vector at a given location. Unfortunately, the surveillance and control programmes of vectors, in particular those of public health concern, have not been established in Qatar to date. The recent concern has arisen because of the Qatar National Vision 2030, which aims to 'transform Qatar into an advanced society capable of achieving sustainable development', and the willingness to fulfil its four pillars, in particular the one on environmental development (GSPD, 2008). Here the impact of climate and environmental changes, in particular urbanisation, requires assessment and mitigation of negative impacts, including of VBDs. In addition, hosting of the 2022 FIFA World Cup Qatar $^{\mathrm{TN}}$ necessitates fulfilling a number or requirements for prevention and preparedness for disease transmission, including VBDs. In light of these requirements this review aims to present an overview of the present status of vectors and VBDs in Qatar, and to identify key challenges and future prospects. The work is based on a vector control situation analysis and needs assessment, performed during and following an expert mission in Qatar, November 2017,

\footnotetext{
${ }^{1} \mathrm{http}: / /$ www.indexmundi.com/facts/qatar.
} known as a source of outbreaks and/or disease persistence

organised by the WHO Eastern Mediterranean Regional Office and achieved in collaboration with the Ministry of Public Health of Qatar and other local stakeholders.

\section{Materials and methods}

Qatar (latitude $24-26^{\circ} \mathrm{N}$, longitude $50-51^{\circ} \mathrm{E}$ ) is located on the north-eastern coast of the Arabian Peninsula, Middle East, and is itself a small peninsula that juts in the Persian Gulf. Qatar sizes approximately $11,600 \mathrm{~km}^{2}$ and is populated by around 2,750,000 of which a large part of migrants that varies from year to year (75.5\% in 2015). ${ }^{1}$ The country is divided into eight municipalities. Qatar's climate is classified as hot desert (Köppen-Geiger category BWh) with annual mean temperature of $27.1{ }^{\circ} \mathrm{C}$ and mean rainfall of $72 \mathrm{~mm}$ (October-May). ${ }^{2}$ The whole population has access to water supply and sanitation. Water (desalinated) of grade 1 is supplied in the residential areas, whereas water of grade 2 (treated grey water) is supplied for animal farms, agriculture, and gardening (Jasim et al., 2016).

The situation of vectors and VBDs of public health importance in Qatar was analysed based on a systematic literature review with sources up to December 31, 2019 accessed. References were identified through searches on OvidSP (Ovid MEDLINE ${ }^{\oplus}$, which includes PubMed, 1946 to present), $\mathrm{CAB}$ direct (full applied life science database), and Web of Science, any language, any year, by use of the following search string: [(vector* OR mosquito* OR culicid* OR phlebotom* OR tick*).af AND Qatar.ti]. Additional references were identified using reference tracking and grey literature (Figure 1 summarises the PRISMA search flow). A portion of the references obtained were excluded if duplicated or when the content was not relevant to our study and a final list of 29 papers was fully assessed. A limited number of published papers containing precise information

${ }^{2}$ https://en.climate-data.org/asia/qatar-183.

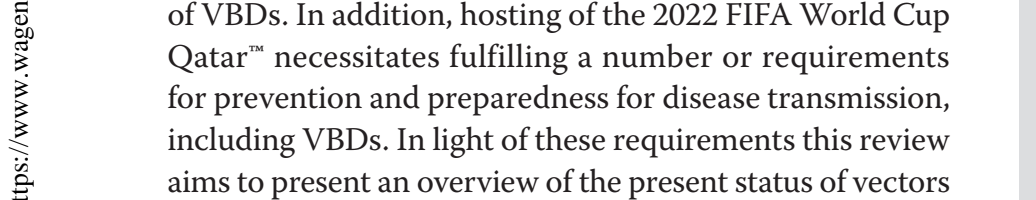
Records identified through
database searching $(n=84)$

Additional records identified
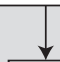

Records after duplicates removed within search string, screened

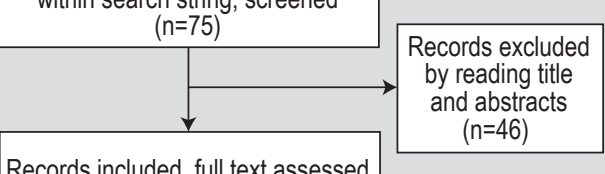

Records included, full text assessed $(n=29)$ other sources $(n=11)$

Figure 1. Flow chart of the literature search on vectors and vector-borne diseases in Qatar. 
on vectors or on VBDs in Qatar were found (13 and 6, respectively). However, it is possible that the references on VBDs were underestimated, because the search string focused primarily on vectors (VBDs names were not included, to avoid collecting clinical case descriptions).

\section{Results}

\section{Importance of vector-borne diseases in Qatar}

The literature reveals that no VBD locally transmitted cases have been recorded in Qatar, but cases were recorded among expatriate workers and travellers who returned from an endemic country. The most important VBDs such as malaria, dengue, leishmaniasis are notifiable in Qatar and investigation on case travel history is performed. However, with the exception of malaria, data on VBD cases remain scarce. No active case detection or special surveys among at-risk population have been done in Qatar. Table 1 lists all VBD pathogens that have been observed or are suspected to occur in the State of Qatar.
While there are no reports of locally acquired cases of VBDs in Qatar in the last two decades, numbers of imported VBD cases have been registered, most of them for malaria parasite infection (Figure 2 and 3). As for mosquitoborne arboviruses, a few dengue, chikungunya, and Zika imported cases were reported in 2016 (Figure 3). More human cutaneous leishmaniasis cases exist, with 4 to 11 per year during the period 2000-2011, but evidence of local transmission exist only for infection of local dogs and cats, with 4 out of 199 animals (2.0\%) recently found positive for Leishmania spp. (Lima et al., 2019).

\section{Malaria}

Qatar has been free from local malaria transmission for almost 50 years, with the last local case reported in 1970 (WHO, 2014b). However, influx of migrant workers from malaria-endemic countries in particular during the last two decades, led to a high number of imported cases, representing a major threat for re-introduction of local transmission (Figure 2) (Al-Kuwari, 2009; Farag et al., 2018;

Table 1. List of vector-borne disease pathogens of public health and animal health importance occurring or at risk for Qatar.

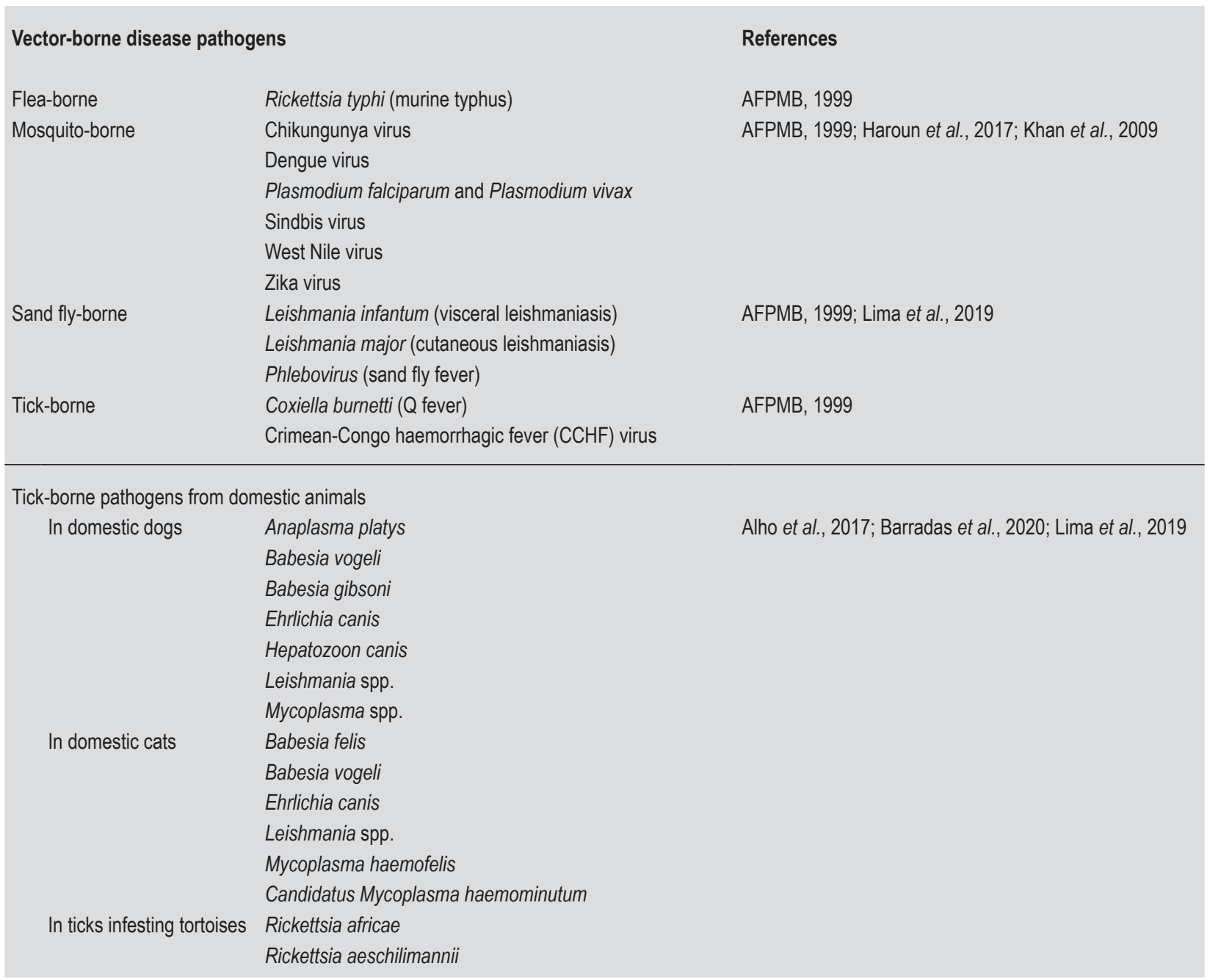




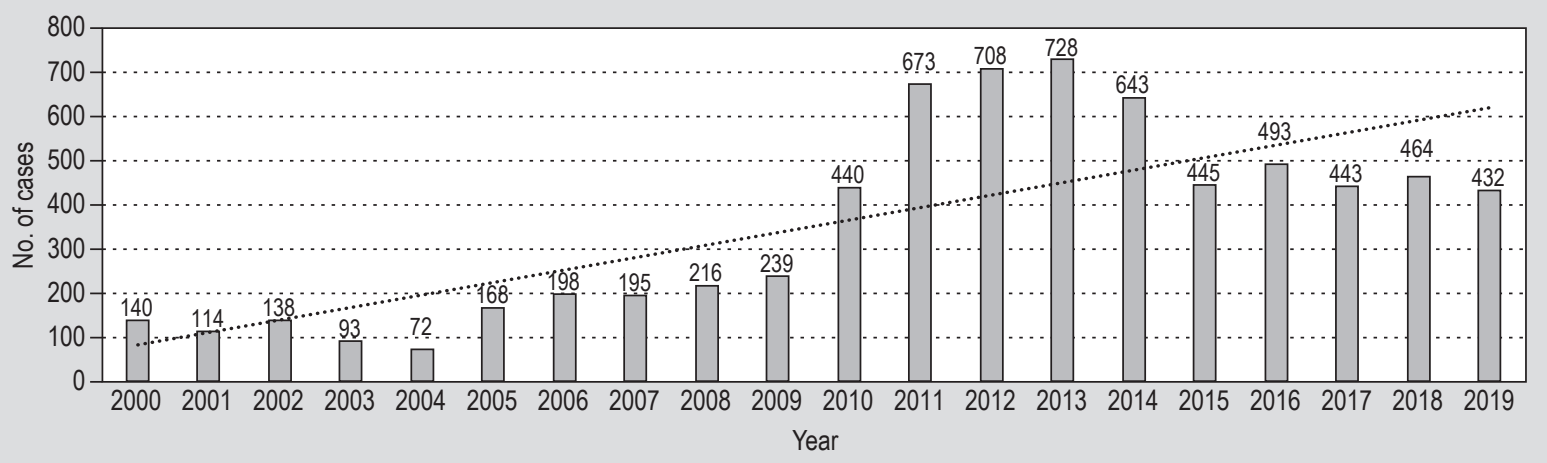

Figure 2. Annual numbers of reported (imported) human malaria cases in Qatar, 2000-2019 (based on data from MoPH of Qatar and WHO EMRO).

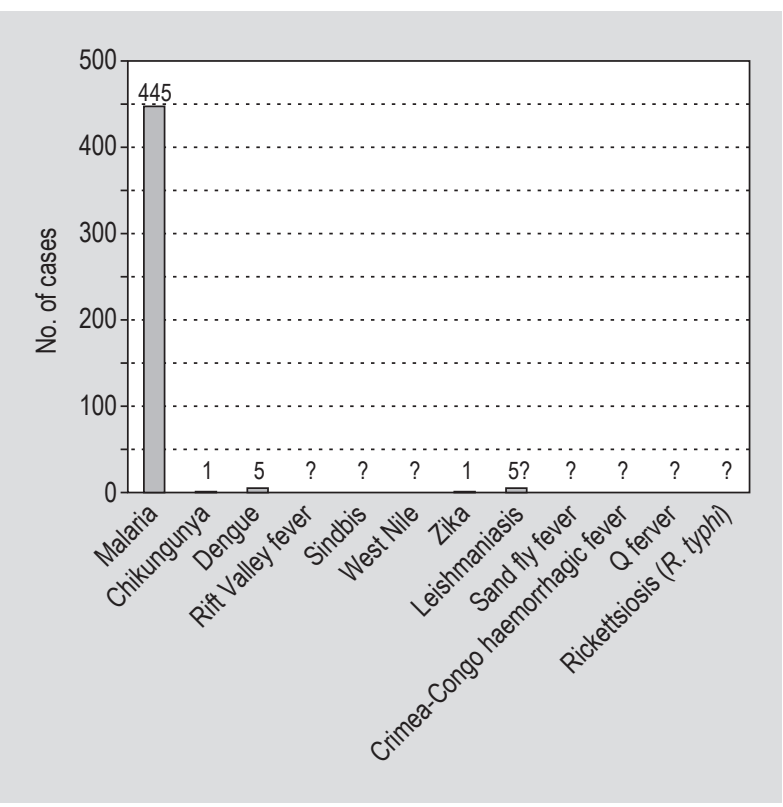

Figure 3. Number of vector-borne disease cases for pathogens reported to occur or have occurred in Qatar, 2016 (based on data from MoPH of Qatar; ? = not or poorly reported).

Khan et al., 2009). Specifically, Plasmodium vivax is the main etiologic agent and most cases occur between August and October, resulting from the importation of infections during summer vacation (Bansal et al., 2017). Furthermore, the presence of malaria vectors e.g. Anopheles (Cellia) stephensi Liston, 1901 in Qatar (Kardousha, 2016; Mikhail et al., 2009), emphasises the receptivity for having local malaria transmission (Khan et al., 2009). This situation is similar to that in other countries of the Arabian Peninsula (Simon et al., 2017).

\section{Dengue and chikungunya}

The viruses responsible for these two infections are primarily transmitted by Aedes (Stegomyia) aegypti (L., 1762) which is reported to occur in Qatar (AFPMB, 1999). Dengue has become endemic in the Eastern Mediterranean region (WHO, 2014a). A recent systematic review of the epidemiology of dengue in the Middle East and neighbouring countries showed a majority of cases being detected along the coastlines of countries bordering the Red and Arabian Seas, and in Pakistan (Humphrey et al., 2016). No data are published for Qatar but a total of 163 dengue cases was reported during 2012-2019 by the Hamad Medical Corporation, Doha, Qatar (unpublished data) and all these cases were imported. Chikungunya infection shows similar clinical presentation to non-severe dengue, which makes its epidemiology uncertain (Kuno, 2015). Recently, many urban outbreaks have occurred in the Indian Ocean region and Latin America (WHO, 2014a), with the largest outbreak in the WHO Eastern Mediterranean Region in Yemen (Malik et al., 2014). However, the current and historical epidemiology of chikungunya in the Arabian Peninsula remains poorly characterised.

\section{Yellow fever}

Yellow fever virus is transmitted mainly by Aedes mosquitoes (Ae. aegypti in the rural/urban cycle) and is endemic to tropical areas of Africa and Latin America, with around 200,000 cases every year (WHO, 2014a). The number of yellow fever cases has increased globally over the past two decades and epidemics occurred in Sudan in recent years (Buliva et al., 2017), but no cases were reported in Qatar during that period.

\section{West Nile (WN) infection and Rift Valley fever (RVF)}

These two mosquito-borne zoonotic viral diseases occur in both temperate and tropical regions. West Nile virus is transmitted by various mosquitoes according to the 
geographical area, but primarily Culex species such as Culex (Culex) quinquefasciatus Say, 1823 and Culex (Culex) tritaeniorhynchus Giles, 1901 (Eybpoosh et al., 2019; Paramasivan et al., 2003). The primary vectors for RVF virus are floodwater Aedes species but other species (Anopheles, Culex) can contribute to transmission during an outbreak (Linthicum et al., 2016). To date, no human cases of WN and RVF have been reported in Qatar. However, recently high seroconversions to $\mathrm{WN}$ virus were observed among horses in Qatar, suggesting a possibility that the virus might be endemic in the country and has a potential to pose risk to human health (DeCarlo et al., 2017; Haroun et al., 2017). The fact that Qatar is a peninsula serving as a bridge and land to several migratory avian species, and that there is an increasing activity of importing wild birds in the country calls for attention to WN epidemiology in the state (QBRC, 2016). It can be advised, from veterinary health standpoint, that all horses that visit Qatar for e.g. equestrian festivals should be vaccinated to prevent disease burden in horses.

\section{Tick-borne diseases}

For all other VBDs that might be likely to occur in Qatar, there is a clear absence of information. Tick-borne pathogens circulate in Qatar (Table 1), with reports of ten different pathogens of veterinary importance in domestic dogs and cats (Alho et al., 2017). Circulation of other pathogens of animal health and public health importance like Crimean-Congo haemorrhagic fever virus has been reported in the Arabian Peninsula (Wernery, 2014), but no information on tick-borne pathogen presence in humans is available from Qatar to date (Al-Abri et al., 2017).

\section{Knowledge of vectors in Qatar}

The review found reports of 29 species of native or introduced arthropods, from families that comprise species recognised to transmit pathogen to human or animal, to occur in Qatar (Table 2). They include 20 mosquito, 2 flea, 1 fly, and 6 tick species (Figure 4). One louse species, Pediculus humanus capitis De Geer, 1767, can be added to the list even without reference, since schools do occasionally notify infestations to the Ministry of Public Health (MoPH), and lice eradication campaigns are promoted (https:// www.gulf-times.com/story/367307/Parents-told-to-checkchildren-s-hair-for-lice). No sand flies are reported and all other groups except mosquitoes are known by little number of species (1 to 6) only. Most of these species (26 out of $30 ; 87 \%$ ) are proven or suspected to transmit at least one pathogen. Only one paper each is reporting fleas and biting flies, while four papers are reporting tick species, and 9 papers are reporting mosquito species occurrences.

\section{Discussion}

\section{Needs for further investigations on vector occurrence in Qatar}

By January 2020, thirty arthropod vector species are reported to occur in Qatar. Although no sand flies are described from Qatar, they certainly occur considering reports of locally acquired Leishmania infections (Lima et al., 2019) and reported presence of many species in neighbouring countries with similar environmental conditions (e.g. 22 and 4 species in Saudi Arabia and United Arab Emirates, respectively) (AFPMB, 1999). Similarly for the latter reason, fleas and ticks are most probably more numerous (25 and 41 species, respectively, reported from Saudi Arabia (AFPMB, 1999)). Among these ticks, two species, Hyalomma aegyptium (L., 1758) and Hyalomma rufipes Koch, 1844 are considered not native from Qatar (Wassef et al., 1997; Barradas et al., 2020). Since they are introduced in the country with their hosts (mammals, birds or reptiles), more studies are needed to collect evidence of their establishment and to determine the species' status in Qatar.

Mosquitoes have been better studied but 7 among the 20 species are reported in single publications, sometimes beyond their previously known natural distribution range (i.e. not known to occur in the Arabic Peninsula, like Aedes (Ochlerotatus) dorsalis (Meigen, 1830) which is a cold-climate species), and thus their presence requires confirmation (Table 2). Also two reported taxa, Culiseta sp. and Coquillettidia sp., remain to be identified to the species level. And here again, in view of the presence of many other species in neighbouring countries (36 species in Saudi Arabia (AFPMB, 1999)), additional species might occur in Qatar. Only one invasive mosquito species, $A e$. aegypti, is recorded so far to have established (AFPMB, 1999). However, the Asian tiger mosquito Aedes (Stegomyia) albopictus (Skuse, 1895) is another invasive species that is spreading worldwide and already found in Middle East (Iran, Gulf of Oman coast; Doosti et al., 2016). Because of intense international trade (cf. Introduction) and countries' climatic suitability for occurrence (Ducheyne et al., 2018), the species could be introduced and then establish and thus its possible presence should be surveyed. In summary, the presence in Qatar of arthropod vector species looks under-recorded to date and field studies are crucially needed to complete the knowledge of species presence/ absence, distribution and abundance as a base for VBD risk assessment (Braks et al., 2011; Sedda et al., 2014; WHO, 2014a).

To date, many of the reported species can be considered as potential vectors, since their confirmed or putative role in transmission of pathogens is well described in the literature (Table 2). The two flea species Ctenocephalides felis felis 
Table 2. Arthropod vector families and their species reported to occur in Qatar.

\begin{tabular}{|c|c|c|c|c|c|c|}
\hline Species & Status & $\begin{array}{l}\text { First } \\
\text { report }\end{array}$ & Host preference ${ }^{1}$ & Larval habitat & Potential vector role ${ }^{2}$ & References for Qatar \\
\hline \multicolumn{7}{|c|}{ Mosquitoes (Diptera: Culicidae) ( $n=20$ spp.) } \\
\hline Aedes aegypti & $\begin{array}{l}\text { Introduced (during } \\
18^{\text {th }} \text { or } 19^{\text {th }} \text { Century) }\end{array}$ & 1999 & Human & Container inhabiting & $\begin{array}{l}\text { Chikungunya, dengue, and Zika viruses; } \\
\text { Dirofilaria immitis filarial worm }\end{array}$ & AFPMB, 1999 \\
\hline Ae. caspius & Native & 2009 & Mammals (birds) & Brackish water flooded areas & Rift Valley fever virus & $\begin{array}{l}\text { Kardousha, 2015, 2016; Mikhail et } \\
\text { al., } 2009\end{array}$ \\
\hline Anopheles culicifacies s.l. & Native & 1999 & $\begin{array}{l}\text { Human (mammals, } \\
\text { birds) }\end{array}$ & $\begin{array}{l}\text { Various standing water bodies, } \\
\text { containers }\end{array}$ & Human malaria & AFPMB, 1999 \\
\hline An. multicolor & Native & 1992 & Mammals & Fresh and brackish waters & (Human malaria?) & $\begin{array}{l}\text { Glick, 1992; Kardousha, 2016; Mikhail } \\
\text { et al., } 2009\end{array}$ \\
\hline An. sergentii & Native & 1992 & Mammals & Fresh waters & (Human malaria) & Glick, 1992 \\
\hline An. stephensi & Native & 1999 & Mammals, birds & Containers, fresh ground waters & Human malaria & $\begin{array}{l}\text { AFPMB, 1999; Kardousha, 2015, 2016; } \\
\text { Mikhail et al., 2009; Rabab, } 2015\end{array}$ \\
\hline Cx. laticinctus & Native & 2015 & Zoophilic & Containers, fresh ground waters & - & Kardousha, 2015 \\
\hline Cx. mimeticus & Presence to be confirmed ${ }^{3}$ & 2015 & Zoophilic (human) & Streams and river bed pools & - & Rabab, 2015 \\
\hline Cx. pipiens s. $.1^{4}$ & Native & 1985 & Human & Containers and ground waters & West Nile and sindbis viruses, filarial worms & $\begin{array}{l}\text { Abdu and Shaumar, 1985; Kardousha, } \\
\text { 2015, 2016; Mikhail et al., } 2009\end{array}$ \\
\hline Cx. perexiguus & Presence to be confirmed ${ }^{3}$ & 2015 & Birds (mammals) & Containers and ground waters & West Nile and sindbis viruses & Kardousha, 2015 \\
\hline Cx. quinquefasciatus & Native & 1988 & Human & Containers and ground waters & West Nile virus, filarial worms & $\begin{array}{l}\text { AFPMB, 1999; Harbach, 1988; } \\
\text { Kardousha, 2015, 2016; Mikhail et al., } \\
\text { 2007, } 2009\end{array}$ \\
\hline Cx. sitiens & Native & 2015 & Birds, pigs (human) & $\begin{array}{l}\text { Brackish ground waters, } \\
\text { containers }\end{array}$ & $\begin{array}{l}\text { (Japanese encephalitis virus?, filarial } \\
\text { worms?) }\end{array}$ & Kardousha, 2015 \\
\hline Cx. tritaeniorhynchus & Native & 2015 & Mammals (human) & Various fresh ground waters & $\begin{array}{l}\text { Japanese encephalitis, Rift Valley, sindbis } \\
\text { and West Nile viruses }\end{array}$ & Kardousha, 2015, 2016 \\
\hline Cx. univittatus & Native & 2009 & Birds (mammals) & Fresh waters & West Nile and sindbis viruses & Kardousha, 2015; Mikhail et al., 2009 \\
\hline Cx. pusillus & Native & 2009 & Zoophilic & Brackish ground waters & - & Kardousha, 2015; Mikhail et al., 2009 \\
\hline Cx. vagans & Presence to be confirmed ${ }^{3}$ & 2015 & Mammals, human & Containers and ground water & Filarial worms & Rabab, 2015 \\
\hline Culiseta sp. & Presence to be confirmed ${ }^{3}$ & 1985 & Birds?, mammals? & Containers & Avian malaria $^{5}$ & Abdu and Shaumar, 1985 \\
\hline No data & Most probably present & - & Birds, mammals, reptiles & Ground with decaying debris & Leishmania spp., phleboviruses & AFPMB, 1999; Cuomo, 2004 \\
\hline \multicolumn{7}{|l|}{ Fleas (Siphonaptera) } \\
\hline Ctenocephalides felis felis & Cosmopolitan & 1999 & Cat & Host & Rickettsia spp., Bartonella spp. & AFPMB, 1999 \\
\hline Xenopsylla cheopis & Cosmopolitan & 1999 & Rat & Host & Yersinia pestis & AFPMB, 1999 \\
\hline \multicolumn{7}{|c|}{ Lice (Phthiraptera: Pediculidae) } \\
\hline Pediculus humanus capitis & Cosmopolitan & $?$ & Human & Host & - & 6 \\
\hline \multicolumn{7}{|c|}{ Biting flies (Diptera: Muscidae) } \\
\hline Stomoxys calcitrans & Cosmopolitan & 1983 & Livestock, human & Livestock dung & $\begin{array}{l}\text { Mechanical transmission of bacteria and } \\
\text { viruses }\end{array}$ & Abdu and Shaumar, 1985 \\
\hline \multicolumn{7}{|l|}{ Hard ticks (Acari: Ixodae) } \\
\hline Hyalomma aegyptium & Introduced on tortoises & 2018 & Tortoises, (human) & Host & $\begin{array}{l}\text { (Borrelia), (Coxiella burnetii), Hemolivia } \\
\text { mauritanica }{ }^{5} \text {, Hepatozoon kisrae } \\
\text { (Rickettsia) }\end{array}$ & $\begin{array}{l}\text { Barradas et al., 2020; Estrada-Peña et } \\
\text { al., } 2017\end{array}$ \\
\hline H. anatolicum anatolicum & Native & 1997 & Livestock, human & Host & $\begin{array}{l}\text { Babesia spp., (CCHF virus), Theileria spp., } \\
\text { (Thogoto virus) }\end{array}$ & $\begin{array}{l}\text { Estrada-Peña et al., 2017; Wassef et } \\
\quad \text { al., } 1997\end{array}$ \\
\hline H. dromedarii & Native & 1997 & Camels, cattle & Host & $\begin{array}{l}\text { CCHF, Dera Ghasi Khan, Dhori, Kadam, } \\
\text { and Sindbis viruses, Coxiella burnetti, } \\
\text { Rickettsia spp., Theilera spp. }\end{array}$ & $\begin{array}{l}\text { Estrada-Peña et al., 2017; Hagras and } \\
\text { Khalil, 1988; Wassef et al., } 1997\end{array}$ \\
\hline H. impeltatum & Native & 1997 & Camels, cattle, sheep & Host & $\begin{array}{l}\text { (CCHF and Wanowrie viruses), Rickettsia } \\
\text { spp., Theileria spp. }\end{array}$ & $\begin{array}{l}\text { Estrada-Peña et al., 2017; Wassef et } \\
\text { al., } 1997\end{array}$ \\
\hline H. marginatum turanicum & Native & 1997 & Camels, cattle, sheep & Host & $\begin{array}{l}\text { Anaplasma spp., Babesia spp., CCHF } \\
\text { virus, Coxiella burneti, Rickettsia spp., } \\
\text { Theileria spp. }\end{array}$ & $\begin{array}{l}\text { Estrada-Peña et al., 2017; Wassef et } \\
\text { al., } 1997\end{array}$ \\
\hline H. rufipes & Introduced? & 1997 & Birds, livestock & Host & $\begin{array}{l}\text { Anaplasma marginale, Babesia occultans, } \\
\text { CCHF virus, Rickettsia conorii }\end{array}$ & $\begin{array}{l}\text { Estrada-Peña et al., 2017; Wassef et } \\
\quad \text { al., } 1997\end{array}$ \\
\hline
\end{tabular}

${ }^{1}$ Host given in brackets are bitten occasionally only.

${ }^{2}$ Only pathogens for which solid suspicion of vector role exists are listed (e.g. infections on the field only or in the lab only are not listed), and pathogens given in brackets are those for which the vector plays a secondary role only. ${ }^{3}$ Single observation.

${ }^{4}$ Includes form pipiens and form molestus.

${ }^{5}$ Of veterinary concern only.

${ }^{6}$ https://www.gulf-times.com/story/367307/Parents-told-to-check-children-s-hair-for-lice; '?' = significant suspicion, but not yet evidenced; CCHF = Crimea-Congo haemorrhagic fever. 


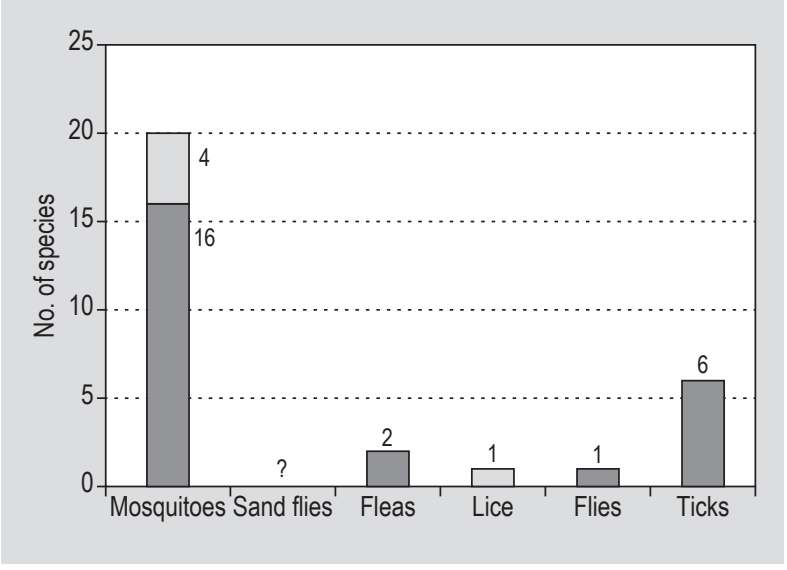

Figure 4. Numbers of species among arthropod vector families reported to occur in Qatar. Dark grey = potential vector species; light grey = non-vector species; ? = not reported.

(Bouché, 1835) and Xenopsylla cheopis (Rothschild, 1903) can transmit pathogens to their animal host (cat and rat, respectively), and the rat flea is the main vector of plague (Yersinia pestis) (Bitam et al., 2010). The head louse $P$. humanus capitis is not proven to act as vector (Badiaga and Brouqui, 2012), but the stable fly Stomoxys calcitrans (Linnaeus, 1758) can occasionally act as mechanical vector for bacteria and viruses (Baldacchino et al., 2013). Among the reported six tick species (Hyalomma spp.), all except $H$. aegyptium are recognised vectors of CrimeanCongo haemorrhagic fever virus, and $H$. aegyptium, Hyalomma anatolicum anatolicum Koch, 1844, Hyalomma marginatum turanicum Pomerantzev, 1946 and H. rufipes can transmit additional pathogens (Barradas et al., 2020; Paștiu et al., 2012; Sajid et al., 2018). Among the 20 reported mosquito species, 16 can be considered as potential vectors, with the most relevant being: Aedes aegypti as vector of chikungunya, dengue, and Zika viruses; Anopheles (Cellia) culicifacies Giles, 1901, Anopheles (Cellia) sergentii (Theobald, 1907) and Anopheles stephensi as vector of human malaria; Aedes (Ochlerotatus) caspius (Pallas, 1771) as vector of Rift Valley fever virus; Culex (Culex) pipiens L., 1758, Cx. quinquefasciatus, Cx. tritaeniorhynchus and Culex (Culex) univittatus Theobald, 1901 as vectors of West Nile virus; Culex (Culex) sitiens Wiedemann, 1828 and $C x$. tritaeniorhynchus as vectors of Japanese encephalitis virus (AFPMB, 1999; Becker et al., 2010; Braack et al., 2018).

\section{Challenges in key prevention and control measures of vector-borne disease in Qatar}

Recent years faced a rise in the number of imported malaria cases (Farag et al., 2018) and introduction of at least one non-native Hyalomma tick species (Barradas et al., 2020). Thus a programme for surveillance and control of VBD vectors should be urgently implemented. The data on VBD pathogen occurrence in Qatar are scarce except for malaria. Hence, emphasis should be placed on dengue, chikungunya, Zika, Crimean-Congo haemorrhagic fever, and Rift Valley fever as well as on leishmaniasis. Serological investigations may be implemented within routine surveillance (all suspected cases) or occasional research studies on human (blind surveys) and imported animal hosts (systematic), in particular camels. As conferred above, the knowledge of vector fauna in Qatar is poor. No data are available for phlebotomine sand flies and data are limited for ticks and probably incomplete for mosquitoes. For the latter, also some species reports are incomplete (limited to genus identification) or doubtful and need to be further investigated. Priorities should target mosquito fauna, sand flies and ticks, for their presence, distribution, abundance (main vector mosquitoes), and frequency of introduction (ticks on animal hosts) in Qatar. In a first step, snapshot surveys may be implemented, targeting specific vector families at suitable environments and during the most favourable periods, using various sampling methods. In a second step, cross-sectional and longitudinal studies may be implemented at selected locations and using the most adapted sampling method according to the targeted vector species.

National coordination for VBD risk assessment and management is lacking. Overall, Qatar benefits currently from a good surveillance of some VBD (malaria) but the actual burden of VBDs could be higher than reported here, since there is under-reporting especially from the private facilities and from where many expatriates may seek health care. The state has some capacities in vector control, but no global plan exists, and vector surveillance is in its infancy. Vector control is currently implemented by municipalities to suppress mosquitoes, flies and cockroaches (e.g. applying Bacillus thuringiensis israelensis as mosquito larvicide and pyrethroids as insect adulticide) but accurate entomological diagnostic is not always supporting insecticide application. Susceptibility of vector populations to insecticides is occasionally assessed by the municipality pest control unit of Doha, and some differences in susceptibility to organophosphates and pyrethroids are found between $C x$. pipiens complex populations (Mikhail et al., 2007). This loss of susceptibility appeals for additional and regular assessment to early detect any further loss of mosquito populations' susceptibility and if so to manage insecticide resistance by adjusting treatment methods (IRAC, 2011), together with the promotion of best practices in public health pesticide management (WHO, 2010). The 2022 FIFA World Cup Qatar will occur during winter (November $21^{\text {st }}-$ December $18^{\text {th }}$ ), which is the cooler but also the rain period. There are chances to get disturbance with mosquitoes and flies, especially house fly. The fly population is overabundant in the animal farm areas, probably due to poor farm management and improper cleaning and disinfection activity. It will be essential to control fly to avoid fly-borne diseases, such Escherichia coli enteritis 
or salmonellosis. The major challenges to confront VBD in Qatar are:

- The absence of national strategy for VBD risk assessment and management. Risk plans or strategy definition are usually engaged subsequently to the occurrence of a local outbreak or obvious evidence of VBD threat; this is here not the case to date, but both Qatar National Vision 2030 and 2022 FIFA World Cup Qatar demand it.

- A limited knowledge on the local situation of vectors and vector-transmitted pathogens. This is highlighted above.

- The absence of integrated vector management (IVM) plan and guidelines. Vector management it very limited at this stage; IVM need to be described for the local context, and to be supported by training and capacity building.

- Inadequate trained human resources for vector surveillance and control. As for IVM, training is crucial to locally build capacity, and competences must be sustained in time.

- Absence of functional intra- and inter-sectoral networking. Local municipalities pest control units do collaborate but more networking is necessary, including with research and health units, private pest control companies and points of entry management agencies (port and airport), to ensure efficient and rational response capacities.

- Absence of international networking. Not all competences are locally available but are accessible through international networking; such networking would also facilitate the information flow on changes in VBD picture.

To take up these major challenges, it appears essential to rapidly develop at central level (ministries) a global strategy for addressing VBDs and coordinating all efforts to be done within an inter-sectoral networking, to achieve a good capacity in VBD management. This needs to define a national plan and priorities, to allocate adequate and sustainable human and financial resources, to adapt policies, and to plan capacity building and collaborations.

A complete VBD risk assessment relies on: (1) a comprehensive picture of presence and abundance of vector species; (2) a comprehensive picture of pathogen circulation; and (3) an estimation of the vectorial capacity of the vector population for a defined pathogen. The latter point is also related to the presence and abundance of susceptible hosts (vector-host ratio and biting rate), and transmission will occur only under favourable environmental and weather conditions that have to be evaluated in regard to both pathogen and vectors. Ideally, competences to address all these factors have to be built locally to be able to rapidly assess a risk once an indicator suggests possible transmission emergence (e.g. a malaria imported case at a place where Anopheles mosquitoes are present and active). Research programmes may be designed to adequately support the risk assessment. Then the risk could be managed by application of mitigation measures (e.g. focal mosquito treatments around the imported case). Additionally, according to the level of risk, vector entomology surveys are suggested to be implemented in Qatar.

\section{Conclusions}

National commitment is a cornerstone to ensure success and sustainability of any disease surveillance programme. Control of VBDs is the collective responsibility of many partners but not only the Ministry of Public Health. Also controlling of vectors by using larvicides and adulticides, which can have severe and adverse effects on public health and environment has to be properly considered in a sustainability perspective. To date, no approved vaccines are available for malaria, dengue, West Nile virus, but they exist for yellow fever and Japanese encephalitis. Thus complementary and alternative solutions to control, manage and prevent VBDs are needed, and a number of recommendations can be suggested (Box 1) to prevent VBD outbreaks during the 2022 FIFA World Cup Qatar

\section{Box 1. Recommendations for addressing vector-borne diseases (VBD) risk in Qatar.}

A number of recommendations can be given in order to strengthen the integrated surveillance and control of vectors, and to ensure effective VBD outbreak preparedness and response, within a 'One Health' approach, by complying with WHO resolutions as addressed in the Global vector control response endorsed by all WHO Member States in 2017 (WHO, 2017) and in the International Health Regulation 2005 (WHO, 2008):

- Define a national integrated strategy for management of VBDs in Qatar, define an integrated plan for the main VBD at risk for the country, identify all contributors and their tasks, build a coordination unit, and allocate adequate financial resources.

- Build capacities in entomology, to increase knowledge of local vector ecology and competences for vector identification and vector surveillance.

- Build capacities in research infrastructure, including laboratory diagnostic, for both molecular detection of pathogens and identification of vectors.

- Develop coordination and enhance national and international collaborations to build intra- and inter-sectoral networking on vectors and pathogens they transmit.

- Build an integrated surveillance and control system of both vectors and pathogens, based on integrated vector management, with prioritised targets in term of vector species, pathogens, and high-risk areas.

- Develop a national public health pesticide management policy, to tackle weaknesses in pesticide use or management, and solve potential problems of impact on human health and non-target organisms.

- Plan an evaluation and quality check process, to adjust the surveillance system when/where needed. 
or any other major local sport event. Qatar has achieved a high rank of developmental rates, and infrastructure construction is going very fast. Accordingly, the population is also increasing by unexpected rates due to the influx of foreign workers originating from various countries, which increases the risk of import of VBD pathogens. This was observed for malaria in 2008-2015 with $99.6 \%$ of the cases being reported in non-Qatari people (Farag et al., 2018). Besides, a huge amount of treated wastewater is now produced. Only 40\% of the effluent water is utilised for different purposes - mainly landscaping - but the majority is dumped out into the open areas around city premises. These wastewater wetlands may provide larval habitats for various mosquito species and therefore should be surveyed, together with the classical urban and suburban mosquito larval habitats. Finally, there is a regular import of animal hosts (e.g. camels) possibly carrying ectoparasites such as ticks, and a surveillance of these hosts and ticks should be implemented in order to detect introduced pathogens of public health importance.

\section{Acknowledgements}

We are grateful to Dr Ghasem Zamani, WHO Eastern Mediterranean Regional Office, Cairo, Egypt; Dr Fatima Abdulla Al-Khayat (Qatar University); Dr Mohamed Nour, Dr Mohammed I Harun, Mr. Redentor Ramiscal, Dr Mueen Qaasim, and Mr. Fareed Abudia (MoPH); Dr Hassan A. Farrag, Dr Murtada Othman Ahmed Al Kagam, Mr Ismaeel Alnagar, and Mr Abdullah Hassan (Al Rayyan Municipality); Mr Abdullah Almuhamdi and Mr Mohamed Alswadi (Doha Municipality) for fruitful discussion and support for field investigations.

\section{Funding}

This work has been mainly funded by WHO Eastern Mediterranean Regional Office. Authors did not have entered into an agreement with the funder that may have limited their ability to complete the research as planned and have had full control of all primary data. In addition DB and EABAF received funds from Qatar National Research Fund (a member of Qatar Foundation) through the NPRP grant (NPRP12S-0310-190284). The findings achieved herein are solely the responsibility of the authors.

\section{Conflict of interest}

The authors declare no competing interests.

\section{References}

Abdu, R.M. and Shaumar, N.F., 1985. A preliminary list of the insect fauna of Qatar. Qatar University Science Bulletin 5: 215-232.
Al-Abri, S.S., Abaidani, I.A., Fazlalipour, M., Mostafavi, E., Leblebicioglu, H., Pshenichnaya, N., Memish, Z.A., Hewson, R., Petersen, E., Mala, P., Nhu Nguyen, T.M., Rahman Malik, M., Formenty, P. and Jeffries, R., 2017. Current status of Crimean-Congo haemorrhagic fever in the World Health Organization Eastern Mediterranean Region, issues, challenges, and future directions. International Journal of Infectious Diseases 58: 82-89.

Al-Kuwari, M.G., 2009. Epidemiology of imported malaria in Qatar. Journal of Travel Medicine 16(2): 119-122.

Alho, A.M., Lima, C., Latrofa, M.S., Colella, V., Ravagnan, S., Capelli, G., Madeira de Carvalho, L., Cardoso, L. and Otranto, D., 2017. Molecular detection of vector-borne pathogens in dogs and cats from Qatar. Parasites \& Vectors 10(1): 298.

Armed Forces Pest Management Board (AFPMB), 1999. Regional disease vector ecology profile. The Middle East. Armed Force Pest Management Board, Defense Pest Management Information Analysis Center, Washington, DC, USA, 209 pp. Available at: https:// permanent.access.gpo.gov/lps28798/mid_east.pdf.

Badiaga, S. and Brouqui, P., 2012. Human louse-transmitted infectious diseases. Clinical Microbiology and Infection 18(4): 332-337.

Baldacchino, F., Muenworn, V., Desquesnes, M., Desoli, F., Charoenviriyaphap, T. and Duvallet, G., 2013. Transmission of pathogens by Stomoxys flies (Diptera, Muscidae), a review. Parasite 20: 26 .

Bansal, D., Acharya, A., Bharti, P.K., Abdelraheem, M.H., Elmalik, A., Abosalah, S., Khan, F.Y., ElKhalifa, M., Kaur, H., Mohapatra, P.K., Sehgal, R., Idris, M.A., Mahanta, J., Singh, N., Babiker, H.A. and Sultan, A.A., 2017. Distribution of mutations associated with antifolate and chloroquine resistance among imported Plasmodium vivax in the State of Qatar. The American Journal of Tropical Medicine and Hygiene 97(6): 1797-1803.

Barradas, P.F., Mesquita, J.R., Lima, C., Cardoso, L., Alho, A.M., Ferreira, P., Amorim, I., De Sousa, R. and Gartner, F., 2020. Pathogenic Rickettsia in ticks of spur-thighed tortoise (Testudo graeca) sold in a Qatar live animal market. Transboundary and Emerging Diseases 67(1): 461-465.

Becker, N., Petrić, D., Zgomba, M., Boase, C., Madon, M. and Kaiser, A., 2010. Mosquitoes and their control. Springer-Verlag, Berlin, Heidelberg, Germany, 577 pp.

Bitam, I., Dittmar, K., Parola, P., Whiting, M.F. and Raoult, D., 2010. Fleas and flea-borne diseases. International Journal of Infectious Diseases 14(8): e667-e676.

Braack, L., Gouveia de Almeida, A.P., Cornel, A.J., Swanepoel, R. and De Jager, C., 2018. Mosquito-borne arboviruses of African origin: review of key viruses and vectors. Parasites \& Vectors 11(1): 29.

Braks, M., Van der Giessen, J., Kretzschmar, M., Van Pelt, W., Scholte, E.-J., Reusken, C., Zeller, H., Van Bortel, W. and Sprong, H., 2011. Towards an integrated approach in surveillance of vector-borne diseases in Europe. Parasites \& Vectors 4(1): 192.

Buliva, E., Elhakim, M., Tran Minh, N.N., Elkholy, A., Mala, P., Abubakar, A. and Malik, S.M.M.R., 2017. Emerging and reemerging diseases in the World Health Organization (WHO) Eastern Mediterranean Region - progress, challenges, and WHO initiatives. Frontiers in Public Health 5: 276-276. 
Cuomo, M.J., 2004. Vector-borne disease ecology of the Middle East. Tulane University \& United States Air Force Biomedical Services Corps, New Orleans, LO, USA, 143 pp. Available at: https://www. patologi.com/MiddleEast_Vector-Borne_Disease_Ecology.pdf.

DeCarlo, C., Omar, A.H., Haroun, M.I., Bigler, L., Bin Rais, M.N., Jalila, A., Omar, A.R. and Mohammed, H.O., 2017. Potential reservoir and associated factors for West Nile virus in three distinct climatological zones. Vector-Borne and Zoonotic Diseases 17(10): 709-713.

Doosti, S., Yaghoobi-Ershadi, M.R., Schaffner, F., Moosa-Kazemi, S.H., Akbarzadeh, K., Gooya, M.M., Vatandoost, H., Shirzadi, M.R. and Mosta-Favi, E., 2016. Mosquito surveillance and the first record of the invasive mosquito species Aedes (Stegomyia) albopictus (Skuse) (Diptera, Culicidae) in Southern Iran. Iranian journal of public health 45(8): 1064-1073.

Ducheyne, E., Tran Minh, N.N., Haddad, N., Bryssinckx, W., Buliva, E., Simard, F., Malik, M.R., Charlier, J., De Waele, V., Mahmoud, O., Mukhtar, M., Bouattour, A., Hussain, A., Hendrickx, G. and Roiz, D., 2018. Current and future distribution of Aedes aegypti and Aedes albopictus (Diptera, Culicidae) in WHO Eastern Mediterranean Region. International Journal of Health Geographics 17(1): 4.

Eder, M., Cortes, F., Teixeira de Siqueira Filha, N., Araújo de França, G.V., Degroote, S., Braga, C., Ridde, V. and Turchi Martelli, C.M., 2018. Scoping review on vector-borne diseases in urban areas, transmission dynamics, vectorial capacity and co-infection. Infectious Diseases of Poverty 7(1): 90.

Estrada-Peña, A., Mihalca, A.D. and Petney, T.N., 2017. Ticks of Europe and North Africa. A guide to species identification. Springer International Publishing, Basel, Switzerland, 404 pp.

Eybpoosh, S., Fazlalipour, M., Baniasadi, V., Pouriayevali, M.H., Sadeghi, F., Ahmadi Vasmehjani, A., Karbalaie Niya, M.H., Hewson, R. and Salehi-Vaziri, M., 2019. Epidemiology of West Nile virus in the Eastern Mediterranean region: a systematic review. PLoS Neglected Tropical Diseases 13(1): e0007081.

Farag, E., Bansal, D., Chehab, M.A.H., Al-Dahshan, A., Bala, M., Ganesan, N., Al Abdulla, Y.A., Al Thani, M., Sultan, A.A. and AlRomaihi, H., 2018. Epidemiology of malaria in the State of Qatar, 2008-2015. Mediterranean Journal of Hematology and Infectious Diseases 10(1): e2018050.

Glick, J.I., 1992. Illustrated key to the female Anopheles of southwestern Asia and Egypt (Diptera, Culicidae). Mosquito Systematics 24(2): 125-153.

GSPD, 2008. Qatar national vision 2030. General Secretariat For Development Planning, Doha, Qatar, 35 pp.

Hagras, A.E. and Khalil, G.M., 1988. Effect of temperature on Hyalomma (Hyalomma) dromedarii Koch (Acari, Ixodidae). Journal of Medical Entomology 25(5): 354-359.

Harbach, R.E., 1988. The mosquitoes of the subgenus Culex in southwestern Asia and Egypt (Diptera, Culicidae). Contributions of the American Entomological Institute 24(1): 1-240.

Haroun, M., Siddiq, A.M., Farag, E.A., Dlissi, E., El Hussein, A.M. and Mohammed, H.O., 2017. Occurrence of equine West Nile virus among horses in Qatar: a preliminary investigation. European Scientific Journal, 13(Special issue): 118-125.
Humphrey, J.M., Cleton, N.B., Reusken, C.B.E.M., Glesby, M.J., Koopmans, M.P.G. and Abu-Raddad, L.J., 2016. Dengue in the Middle East and North Africa: a systematic review. PLoS Neglected Tropical Diseases 10(12): e0005194.

IRAC, 2011. Prevention and management of insecticide resistance in vectors of public health importance. Insecticide Resistance Action Committee ( $2^{\text {nd }}$ Ed.), 71 pp. Available at: https://www.irac-online. org/content/uploads/VM-Layout-v2.6_LR.pdf.

Jasim, S.Y., Saththasivam, J., Loganathan, K., Ogunbiyi, O.O. and Sarp, S., 2016. Reuse of treated sewage effluent (TSE) in Qatar. Journal of Water Process Engineering 11: 174-182.

Kardousha, M.M., 2015. Additional records of vector mosquito diversity collected from $\mathrm{Al}$ Khor district of North-eastern Qatar. Asian Pacific Journal of Tropical Disease 5(10): 804-807.

Kardousha, M.M., 2016. First report of some adult mosquitoes captured by CDC gravid traps from North-Eastern Qatar. Asian Pacific Journal of Tropical Disease 6(2): 100-105.

Khan, F.M., Lutof, A.K., Yassin, M.A., Khattab, M., Saleh, M., Rezeg, H.Y. and Almaslamani, M., 2009. Imported malaria in Qatar; a one year hospital based study in 2005. Travel Medicine and Infectious Disease 7(2): 111-117.

Kuno, G., 2015. A re-examination of the history of etiologic confusion between dengue and chikungunya. PLoS Neglected Tropical Diseases 9(11): e0004101.

Lima, C., Colella, V., Latrofa, M.S., Cardoso, L., Otranto, D. and Alho, A.M., 2019. Molecular detection of Leishmania spp. in dogs and a cat from Doha, Qatar. Parasites \& Vectors 12(1): 125.

Linthicum, K.J., Britch, S.C. and Anyamba, A., 2016. Rift Valley fever, an emerging mosquito-borne disease. Annual Review of Entomology 61(1): 395-415.

Malik, M.R., Mnzava, A., Mohareb, E., Zayed, A., Al Kohlani, A., Thabet, A.A.K. and El Bushra, H., 2014. Chikungunya outbreak in Al-Hudaydah, Yemen, 2011: Epidemiological characterization and key lessons learned for early detection and control. Journal of Epidemiology and Global Health 4(3): 203-211.

Mikhail, M.W., Al-Bursheed, K.M., Abd El-Halim, A.S. and Morsy, T.A., 2009. Studies on mosquito borne dieases in Egypt and Qatar. Journal of the Egyptian Society of Parasitology 39(3): 745-756.

Mikhail, M.W., Al-Bursheed, K.M. and Allam, K.A.M., 2007. Susceptibility of Culex pipiens complex to some insecticides in Qatar. Journal of the Egyptian Society of Parasitology 37(3): 893-902.

Paramasivan, R., Mishra, A.C. and Mourya, D., 2003. West Nile virus, the Indian scenario. The Indian journal of medical research 118: 101-108.

Paștiu, A.I., Matei, I.A., Mihalca, A.D., D’Amico, G., Dumitrache, M.O., Kalmár, Z., Sándor, A.D., Lefkaditis, M., Gherman, C.M. and Cozma, V., 2012. Zoonotic pathogens associated with Hyalomma aegyptium in endangered tortoises: evidence for host-switching behaviour in ticks? Parasites \& Vectors 5(1): 301.

QBRC., 2016. Qatar birds list. Qatar Bird Records Committee , Doha, Qatar. Available at: http://www.qatarbirds.org/list.htm.

Rabab, I.A., 2015. The most common mosquitoes at Al-Rayyan municipality (Qatar state) and their potential for transmitting malaria. Msc thesis, Qatar University, Doha, Qatar, 108 p. 
Sajid, M.S., Kausar, A., Iqbal, A., Abbas, H., Iqbal, Z. and Jones, M.K., 2018. An insight into the ecobiology, vector significance and control of Hyalomma ticks (Acari, Ixodidae): a review. Acta Tropica 187: 229-239.

Sedda, L., Morley, D.W., Braks, M.A.H., De Simone, L., Benz, D. and Rogers, D.J., 2014. Risk assessment of vector-borne diseases for public health governance. Public Health 128(12): 1049-1058.

Simon, B., Sow, F., Al Mukhaini, S.K., Al-Abri, S., Ali, O.A.M., Bonnot, G., Bienvenu, A.-L, Petersen, E. and Picot, S., 2017. An outbreak of locally acquired Plasmodium vivax malaria among migrant workers in Oman. Parasite 24: 25.

Tatem, A.J., Rogers, D.J. and Hay, S., 2006. Global transport networks and infectious disease spread. In: Hay, S.I., Graham, A. and Rogers, D.J. (eds.) Global mapping of infectious diseases: methods, examples and emerging applications. Academic Press, London, UK, pp. 293-343.

Valenzuela, J.G. and Aksoy, S., 2018. Impact of vector biology research on old and emerging neglected tropical diseases. PLoS Neglected Tropical Diseases 12(5): e0006365.
Wassef, H.Y., Büttiker, W. and Gallagher, M.D., 1997. Further records of ticks (Acari, Argasidae and Ixodidae) from the Arabian Peninsula. In: Krupp, F. and Mahnert, V. (eds.) Fauna of Saudi Arabia, volume 16. Pro Entomologica, Naturhistorisches Museum, Basel, Switzerland, pp. 63-88.

Weaver, S.C., 2013. Urbanization and geographic expansion of zoonotic arboviral diseases, mechanisms and potential strategies for prevention. Trends in Microbiology 21(8): 360-363.

Wernery, U., 2014. Zoonoses in the Arabian Peninsula. Saudi Medical Journal 35(12): 1455-1462.

World Health Organization (WHO), 2008. International Health Regulations (2005). WHO, Geneva, Switzerland, 74 pp.

World Health Organization (WHO), 2010. Guidelines on public health pesticide management policy. World Health Organization Regional Office for South-East Asia \& WHO Pesticide Evaluation Scheme (WHOPES), New Delhi, India, 50 pp.

World Health Organization (WHO), 2014a. A global brief on vectorborne diseases. WHO, Geneva, Switzerland, 54 pp.

World Health Organization (WHO), 2014b. Malaria in the Eastern Mediterranean Region 2013. World Health Organization Regional Office for the Eastern Mediterranean, Cairo, Egypt, 71 pp.

World Health Organization (WHO), 2017. Global vector control response 2017-2030. WHO, Geneva, Switzerland, 51 pp. 
